\title{
Early childhood factors associated with obesity at age 8 in Vietnamese children: The Young Lives Cohort Study
}

\author{
Tuyen Nguyen ${ }^{1 *}$, Karen Sokal-Gutierrez ${ }^{2}$, Maureen Lahiff ${ }^{3}$, Lia Fernald ${ }^{4}$ and Susan L. Ivey ${ }^{5}$
}

\begin{abstract}
Background: Over recent decades, Vietnam has experienced rapid economic growth, a nutrition transition from the traditional diet to highly-processed and calorie-dense foods and beverages, and an increasing prevalence of childhood overweight/obesity (ow/ob). The goal of this study is to describe the patterns of ow/ob in a longitudinal sample of Vietnamese children from ages 1 to 8, and the sociodemographic and behavioral factors associated with ow/ob at age 8.

Methods: This study is a secondary data analysis of a geographically-representative, longitudinal cohort of 1961 Vietnamese children from the Young Lives Cohort Study from 2002 to 2009. Thirty-one communities were selected with oversampling in rural communities, and children age 1 were recruited from each community using simple random sampling. Surveys of families and measurements of children were collected at child ages 1, 5, and 8. Our specified outcome measure was childhood ow/ob at age 8, defined by the World Health Organization's thresholds for body-mass-index (BMI) for age Z-scores. Associations between early and concurrent socio-behavioral factors, childhood nutrition and physical activity variables were analyzed using STATA 15. Bivariate and multivariable analyses were completed utilizing logistic regression models.
\end{abstract}

Results: The prevalence of ow/ob increased from 1.1\% in both sexes at age 1 to $7 \%$ in females and $13 \%$ in males at age 8 . Bivariate analyses show greater likelihood of ow/ob at age 8 was significantly associated with early life sociodemographic factors (at age 1), male sex $(\mathrm{OR}=2.2,1.6-3.1)$, higher wealth $(\mathrm{OR}=1.1-1.4)$, and urban residence $(\mathrm{OR}=4.3,3-6)$. In adjusted analyses, ow/ob at age 8 was associated with early nutrition practices at age 5 , including frequent consumption of powdered milk $(O R=2.8,1.6-4.6)$, honey/sugar $(O R=2.7,1.8-4.1)$, prepared restaurant/fast foods $(O R=4.6,2.6-8.2)$, and packaged sweets $(O R=3.4,2.3-4.9)$. In addition, breastfeeding for 6 months or longer was protective against obesity at age $8(\mathrm{OR}=0.3,0.1-0.9)$.

Conclusions: We found that increased consumption of powdered milk, honey/sugar, packaged sweets, and prepared restaurants/fast foods are associated with childhood ow/ob. In contrast, breastfeeding for 6 months or longer was protective against childhood ow/ob. These findings suggest that public health programs and campaigns aimed to prevent childhood ow/ob in Vietnam should target early feeding practices.

Keywords: Childhood, Obesity, Overweight, Vietnam, Young lives

\footnotetext{
* Correspondence: nguyenxtuyen@gmail.com

${ }^{1}$ School of Public Health and School of Medicine, UC Berkeley-UCSF Joint Medical Program, University of California, 2121 Berkeley Way, Room 5302, Berkeley, CA, USA

Full list of author information is available at the end of the article
}

(C) The Author(s). 2021 Open Access This article is licensed under a Creative Commons Attribution 4.0 International License, which permits use, sharing, adaptation, distribution and reproduction in any medium or format, as long as you give appropriate credit to the original author(s) and the source, provide a link to the Creative Commons licence, and indicate if changes were made. The images or other third party material in this article are included in the article's Creative Commons licence, unless indicated otherwise in a credit line to the material. If material is not included in the article's Creative Commons licence and your intended use is not permitted by statutory regulation or exceeds the permitted use, you will need to obtain permission directly from the copyright holder. To view a copy of this licence, visit http://creativecommons.org/licenses/by/4.0/ The Creative Commons Public Domain Dedication waiver (http://creativecommons.org/publicdomain/zero/1.0/) applies to the data made available in this article, unless otherwise stated in a credit line to the data. 


\section{Background}

Over recent decades, many low- and middle-income countries (LMICs), such as Vietnam, have experienced rapid economic growth, particularly in urban areas [1]. This pattern has contributed to nutritional disparities and a "double-burden of child malnutrition," with persistent undernutrition and increasing overweight/obesity (ow/ob) [2]. The prevalence of overweight and obesity among children less than 5 years of age has more than doubled, from $2.6 \%$ in 2000 to $5.9 \%$ in 2017 in Vietnam, estimated using World Health Organization's Child Growth Standard between 2000 and 2017 [3].

Child obesity is associated with chronic health problems during childhood and increased risk for adult obesity and chronic diseases, including type 2 diabetes, hypercholesterolemia, cardiovascular disease, fatty liver, sleep apnea, and musculoskeletal disorders [4-6]. Furthermore, early childhood-onset obesity is associated with increased risk of premature mortality compared to adult-onset obesity [7-9]. In Vietnam, a case-control study from 2017 in Hanoi with children 6-11 years of age found that children with obesity tend to have more visceral fat than subcutaneous fat [10]. This difference is associated with increased levels of blood triglycerides and hypertriglyceridemia [10], which leads to increased risk of cardiovascular disease later in life.

Studies attribute the high prevalence of child obesity worldwide to economic globalization, driving a complex array of environmental and behavioral changes - primarily a "nutrition transition" from traditional diets high in carbohydrates and vegetables to diets with more animal products, ultra-processed foods, and high in fats and sugar [11-13]. This is also seen in Vietnam, along with other factors that have been linked to childhood obesity, including decreased physical activity due to greater availability of motor vehicle transportation, and increased sedentary screen-based entertainment $[14,15]$. These economic and behavioral changes, and increasing child obesity, predominately impact urbanized areas and higher social economic strata [16-18].

Though there has been a surge in the number of cross-sectional studies exploring the prevalence and causes of ow/ob in Hanoi and Ho Chi Minh City, there is a lack of longitudinal studies that follow a cohort of children to examine the factors that contribute to this rapid increase in ow/ob. In order to develop effective strategies to prevent child obesity in Vietnam and its health consequences, there is a need for longitudinal data identifying the specific community-, family-, and child-level risk factors associated with childhood obesity across a broader span of early childhood years.

The goal of this study is to describe the patterns of ow/ob in a cohort sample of Vietnamese children at ages 1,5 , and 8 . Additionally, our goal is to examine early (variables at ages 1 and 5) and concurrent (variables at age 8 ) socio-behavioral risk factors associated with child ow/ob at age 8 .

\section{Methods}

\section{Data source}

This was a secondary data analysis of a longitudinal dataset of Vietnamese children and their families in the Young Lives Cohort Study (YLCS) (https://www. younglives.org.uk). YLCS is an international longitudinal research project spearheaded by the University of Oxford in collaboration with research institutes, universities and NGOs in four study countries. YLCS followed a large multi-national cohort of 12,000 children for 15 years in Peru, Ethiopia, India, and Vietnam with the goal of providing researchers information on individual children, their families, and communities to explore causes and consequences of childhood poverty, health \& nutrition, and impacts on child development. For the purposes of our study, we chose to focus on YLCS's Vietnam data.

\section{Study design, population, and setting}

YLCS's Vietnam study sites were selected in 2001 using a sentinel site surveillance system sampling approach discussed in YLCS's technical note [19]. This methodology is multistage, purposive and random sampling that randomizes households from a study site chosen based on predetermined criteria from YLCS. First, five provinces were selected to be geographically representative of regions from North, Central, and South Vietnam Hung Yen, Lao Cai, Da Nang, Phu Yen, and Ben Tre. These five provinces were chosen to include urban, rural, and mountainous regions that also reflect the heterogeneity of ethnicity and religion in Vietnam's populations. In alignment with YLCS's intention to study causes and consequences of children poverty, provincial government staff helped researchers select sentinel sites in each province with the intention of using "over-poor sampling strategy" [19]. This strategy entailed selecting four communes in each province with two communes from the poor group, as ranked by the Provincial Committee for Population of each province, one from the average group, and one from above-average group. However, if a selected commune had a population of less than 6000 persons, a similar commune of the same poverty level was selected to ensure that 100 children could be enrolled from that sentinel site. In total, thirty-one communes were selected to form 20 sentinel sites, with fifteen communes from the lowest-income group (48\%), nine communes from the average-income group (29\%), and seven communes from the above-average income group (23\%). In each commune, a door-to-door screening survey for children born between January 2001 and 
May 2002 was performed from April to June 2002 to produce a list of eligible children. The non-response rate, noted as refusals by caregivers, was less than $2 \%$ (a total of 36 refusals). From each sentinel site, 100 children were randomly sampled using simple random sampling [19].

\section{Data collection}

Three rounds of quantitative surveys of children and households were collected over 8 years: in 2002 (round 1, child age 1), 2006 (round 2, child age 5), and 2009 (round 3, child age 8). Of the 2000 children recruited in round 1, there was $98 \%$ follow-up, and the final sample upon completion of round 3 was 1961 children (Fig. 1).

\section{Anthropometric variables}

Children were weighed and measured according to World Health Organization (WHO) standards. Bodymass-index (BMI) for age Z-score was calculated using WHO AnthroPlus [20]. The outcome variable was child ow/ob defined according to WHO thresholds [21]: For children under age 5 [22], overweight is $\mathrm{BMI}>2$ and $\leq 3$ Z-score, and obesity is BMI $>3$ Z-score; For children ages 5-19 [23], overweight is BMI $>1$ and $\leq 2$ Z-score, and obesity is BMI $>2 \mathrm{Z}$-score. Since the proportions of children with overweight and obesity were relatively small, we combined overweight and obese categories to produce the binary outcome variable of "overweight/ obese" (ow/ob) for logistic regression.

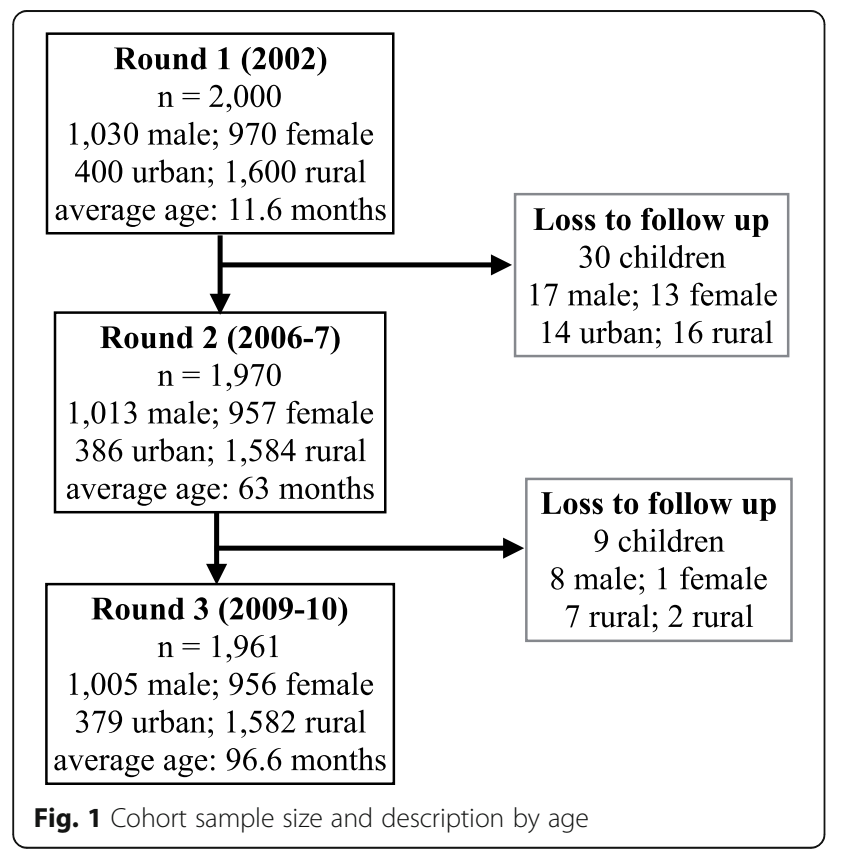

\section{Variables}

The outcome of interest in this study is ow/ob at age 8 as described in the anthropometric variables section above. Independent nutrition and physical activity variables were chosen based on causal pathways and associations previously supported by literature and available data from YLCS [24].

The only nutrition variable from age 1 is length of breastfeeding (less than 6 months, 6-12 months, and greater than 12 months). Beyond age 1 , the questionnaire collected information at age 5 and 8 on frequency of consumption of powdered milk, milk/milk products, packaged sweets/snacks, honey/sugar, and food from restaurants/food stalls. For these variables in our bivariate analyses and parsimonious analyses (Table 3), the sample was divided into quartiles, based on reported frequency over the last 2 weeks. The two exceptions were for number of times a child ate per day at age 5 and 8 , and frequency of consumption of powdered milk at age 8 . For number of times a child ate per day, we chose 3 to be the reference since this would correspond with breakfast, lunch, and dinner. At age 8 , because so few children drank powdered milk, it was only possible to analyze frequency in two groups-above and below the median-instead of quartiles.

For our extended multivariable analyses (Table 4), we found that the nutrition variables divided into quartiles as described above (including consumption of packaged sweets, restaurant/food stalls, sugar/ honey, and powdered milk) did not work for these models because the sample cells of each quartile became too small for comparison. In order to observe the main overall effect and interaction of these nutrition variables, we split them into two groups down the median, instead of quartiles. Subsequently, we created new indicator variables that compared the children in the group above the median to the group of children who were below the median specifically for these analyses.

Physical activity variables collected at age 5 and 8 were not direct measurements of physical activity, so we chose mode of transportation to school, hours spent playing in the last week, and number of TVs owned in household as proxy variables. For mode of transportation to school, we used walking to school as a reference in comparison to being driven by motorbike. For the variables of hours spent playing in the last week and number of TVs owned per household, we divided the sample into tertiles.

The frequencies of nutrition and physical activity variables can be found in the supplemental appendix (Table 3.1). 


\section{Statistical analysis}

All statistical analyses were conducted in the statistical program STATA 15 (College Station, Texas). We divided the data by collection rounds. Within each round, the variables were grouped into child characteristics (including child sex, nutrition, and physical activity), maternal and household characteristics, and neighborhood characteristics.

The sociodemographic covariates were divided into child, household, and community characteristics. At the child level, we included sex, since male sex was positively associated with ow/ob. At the household level, we adjusted for wealth index [25] (a measurement of socioeconomic status calculated as an average of the housing quality index, consumer durables index and services index), since higher wealth index was positively associated with ow/ob. According to a technical report from YLCS, the wealth index was constructed based on previous work from the World Bank and Macro International's wealth index cited in UNICEF's Multiple Indicator Survey [26]. The average of the three indices discussed produces a score between 0 and 1 , in which a higher score indicates a higher socio-economic status. At the community level, we adjusted for urban or rural site type, since urban location was positively associated with ow/ob.

To determine whether to model log odds as a linear function of a continuous variable or to create categories, we examined the LOWESS (Locally Weighted Scatterplot Smoothing) plots of the log odds for the nutrition and physical activity variables. If the resulting graph showed an approximately linear relationship, the variable was taken as continuous. If the graph did not show an approximately linear relationship, the variable was recorded into categories that were modeled with indicator variables, as supported by previous literature. Ow/ob at age 8 was a binary outcome.

We completed bivariate analyses using logistic regression to explore the associations of each independent nutrition and physical activity variable with the child's ow/ob status at age 8 . If the variable showed statistical significance ( $p$-value $<0.05)$, we then included it in our adjusted model (adjusting for the covariates sex, wealth index, site type, and interaction between wealth index and site type) shown in the parsimonious model in Table 3.

We created two extended multivariable models to investigate the individual contribution of nutrition and physical activity variables in relation to each other and their associations with ow/ob at age 8, adjusting for the same sociodemographic covariates from the parsimonious models (sex, wealth index, site type, and interaction term between wealth index and site type). Model 1 examined earlier data collected at age 1 (round 1) and age 5 (round 2) found to be significantly associated with ow/ob at age 8 (round 3) in the adjusted model. Model 2 combined data collected at age 8 (round 3), age 5 (round 2 ), and age 1 (round 1) found to be significantly associated with ow/ob at age 8 (round 3 ) in the adjusted model.

\section{Results \\ Descriptive results}

The mean household size is 4.6 people, with $80 \%$ of the households located in a rural site (Table 1). Mothers had a mean age of 27, mean education of 7 th grade, and average of 2 children. There was a roughly equal distribution of female and male children. One in 8 children was born prematurely. Nearly all children (98\%) were breastfed, and most (93\%) were breastfed for more than 12 months.

The prevalence of childhood ow/ob increased with each round of data collection: age 1 (1.1\%), age $5(8.4 \%)$, and age 8 (10.3\%). Using a Chi-square test and stratifying ow/ob by sex reveals that between age 1 and 5, there was statistical significance in rates of increase for ow/ ob-by age 5, boys had twice the rate of ow/ob than girls, and this two-fold disparity was maintained from 5 to 8 years of age (Fig. 2).

Additionally, 50\% of the children with ow/ob at age 1 continued to be ow/ob at age 5 . And of the children with ow/ob at age $5,65 \%$ continued to be ow/ob at age 8 .

\section{Bivariate analysis: Sociodemographic and behavioral associations}

Child ow/ob at age 8 was associated with numerous variables, including family sociodemographic, child characteristics, household characteristics, and child nutrition and physical activity characteristics (Appendix, Supplemental Table 2.1). Using bivariate analyses, the variables that were statistically significant were then added to the multivariable regression (section $\mathrm{c}$ ) and multivariable models (section d).

The key associations in our bivariate analysis at age 1 was that breastfeeding for longer than 6 months was associated with decreased odds of ow/ob, compared to children who were breastfed for less than 6 months.

At age 5 , ow/ob at age 8 was associated with owning a TV at home for household characteristics. For nutrition variables, the outcome was associated with being in the highest quartile for consumption of powdered/formula milk, packaged sweets, and prepared foods from restaurants/food stalls. Eating more than 6 times per day was also associated with higher odds of being ow/ob at age 8 . As for physical activity variables that were statistically significant in the bivariate analysis at this age was being driven to school by motorbike, compared to walking. In contrast, spending 10 or more hours playing in the 
Table 1 Maternal and child characteristics at baseline (age 1)

\begin{tabular}{|c|c|c|}
\hline Variables & & $\begin{array}{l}\text { Mean }+ \text { SD or N (\%) } \\
(n=1961)\end{array}$ \\
\hline \multirow[t]{5}{*}{ Household } & Household size & $4.6 \pm 1.4$ \\
\hline & Wealth index & $0.5 \pm 0.2$ \\
\hline & Site type & \\
\hline & Urban & $400(20)$ \\
\hline & Rural & $1600(80)$ \\
\hline \multirow[t]{3}{*}{ Maternal } & Age of mother & $27.2 \pm 5.8$ \\
\hline & Highest maternal education (grade) & $6.8 \pm 3.8$ \\
\hline & Number of children born to mother & $1.9 \pm 1.2$ \\
\hline \multirow[t]{18}{*}{ Child } & Sex & \\
\hline & Male & $1005(51.2)$ \\
\hline & Female & $956(48.8)$ \\
\hline & Child age (months) & \\
\hline & Round 1 & $11.6 \pm 3.2$ \\
\hline & Round 2 & $63.0 \pm 3.8$ \\
\hline & Round 3 & $96.6 \pm 3.8$ \\
\hline & Birthweight (grams) & $3100.2 \pm 446.7$ \\
\hline & Ever breastfed & $1893(98.3)$ \\
\hline & Length of time breastfed (months) & \\
\hline & $0-<6$ months & $38(1.9)$ \\
\hline & $6-12$ months & $96(4.9)$ \\
\hline & $12+$ months & $1828(93.2)$ \\
\hline & Born premature & $245(12.5)$ \\
\hline & Prevalence of overweight \& obesity & \\
\hline & Round 1 & $22(1.1)$ \\
\hline & Round 2 & $165(8.4)$ \\
\hline & Round 3 & $199(10.3)$ \\
\hline
\end{tabular}

Oaverweight and obesity is defined using WHO's definition. Less than 5 years of age, overweight is > 2+ SD BMI for age Z-score; obese > 3 + SD. Age 5-19, overweight is > 1+ SD; obese is > 2+ SD

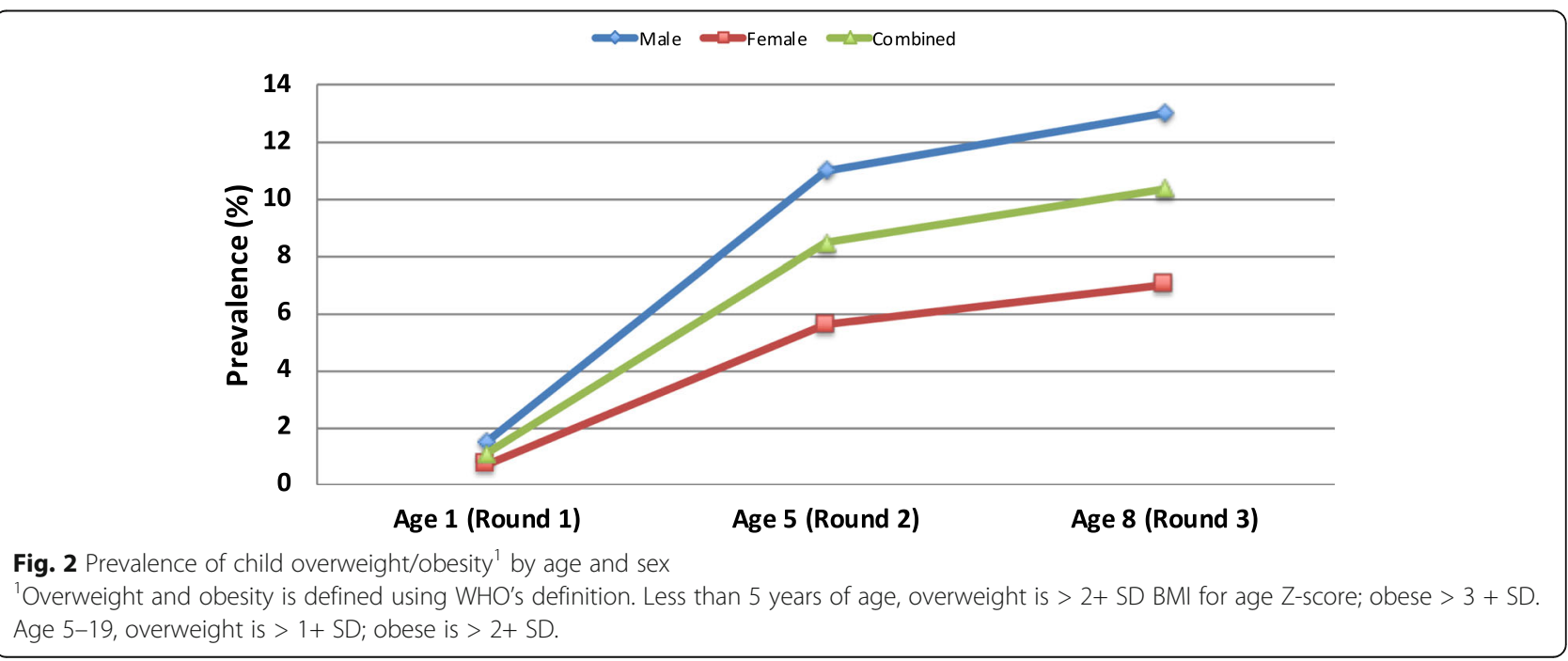


previous week was associated with decreased odds of ow/ob, compared with children who spent less time playing.

At age 8, nutrition factors associated with ow/ob at age 8 included being in the highest quartile for consumption of soft drinks, packaged sweets, and prepared foods from restaurants/food stalls in the last 2 weeks. Additionally, eating more than 6 times per day and having sugary drinks in the last $24 \mathrm{~h}$ were also associated with higher odds. Similar to age 5, transportation to school via motorbike was associated with ow/ob at age 8 .

\section{Multivariable regression: Sociodemographic and behavioral associations}

All odds ratios are reported with 95\% confidence intervals. Using logistic regression, the sociodemographic variables significantly and positively associated ( $p$-value $<$ $0.001)$ with ow/ob at age 8 were male sex $(\mathrm{OR}=2.2$, 1.6-3.1), urban site $(\mathrm{OR}=4.3,3-6)$, and wealth index (Table 2).

Testing for interaction between our covariates, we found the association between ow/ob and wealth index was greater for urban (OR 1.4, 1.3-1.6) communities than rural (OR 1.1, 1.1-1.2). Therefore, we kept this interaction term in our models.

Additionally, we found an association between ow/ob and transportation to school via motorbike was greater for rural children (OR 1.13, 1.02-1.2) than urban children (OR 1.10, 1.002-1.22), with an overall p-value of 0.06 . Since this difference is small and at the 100th decimal point, we did not keep this interaction term in our model.

Adjusting for sociodemographic variables (sex, site type, and wealth index), we examined associations between nutrition and physical activity variables at each round separately with ow/ob at age 8 . Key findings that are potentially modifiable factors for future interventions are discussed in this section (Table 3).

Table 2 Sociodemographic associations with child overweight/ obesity at age 8

\begin{tabular}{ll}
\hline Variables & Odds Ratio ${ }^{\mathrm{a}}[\mathbf{9 5 \%} \mathrm{Cl}]$ \\
\hline Sex (Boy) & $2.2[1.6-3.1]^{* * *}$ \\
Site type (Urban) & $4.3[3-6]^{* * *}$ \\
Wealth index (5\% increase) & \\
Urban WI & $1.4[1.3-1.6]^{* * *}$ \\
Rural Wl & $1.1[1.1-1.2]^{* * *}$ \\
\hline
\end{tabular}

${ }^{\mathrm{a}}$ The odds ratio for each variable is found after adjusting for the other socio-demographic variables in this table

${ }^{*} p<0.05 ;{ }^{* *} p<0.01 ;{ }^{* * *} p<0.001$

\section{Nutrition variables (associated with ow/Ob at age 8)}

Age 1 At age 1, children who breastfed for 6 months or longer had approximately $1 / 3$ the odds $(\mathrm{OR}=0.3,0.1$ 0.9 ) of becoming ow/ob at age 8 , compared to children breastfed for less than 6 months.

Age 5 At age 5, being in the highest quartile for consumption of honey/sugar, milk/milk products, powdered milk or packaged sweets/snacks was significantly associated with higher odds of ow/ob. Children in the highest quartile for consumption of honey/sugar or powdered milk had nearly 3 times the odds of ow/ob $(\mathrm{OR}=2.7$, $1.8-4.1$ and $\mathrm{OR}=2.8,1.6-4.6$ respectively), and those in the highest quartile for consumption of milk/milk products had almost 4 times the odds of ow/ob $(\mathrm{OR}=3.9$, 1.6-4.2), compared to children in the lowest quartile of consumption. Children in the highest quartile for frequency of eating out at restaurants/food stalls had nearly 5 times the odds of ow/ob $(\mathrm{OR}=4.6,2.6-8.2)$ while those in the highest quartile for packaged sweets/snacks had 3 times the odds of ow/ob $(\mathrm{OR}=3.4,2.3-4.9)$, compared to children in the lowest quartile. Lastly, children who ate 6 times or more in the last $24 \mathrm{~h}$ had over twice the odds of ow/ob $(\mathrm{OR}=2.4,1.3-4.6)$, compared to children who ate fewer times.

Age 8 At age 8, children who consumed powdered milk more frequently than the median had nearly twice the risk of ow/ob $(\mathrm{OR}=1.8,1.1-3.0)$, compared to children who drank powdered milk less frequently. Additionally, children who ate 6 times or more daily had over 3 times the odds of ow/ob $(\mathrm{OR}=3.2,1.6-6.8)$, compared to children who ate fewer times. Children in the highest quartile for frequency of eating in restaurant/food stalls or packaged sweets/snacks had nearly 3 times the odds of ow/ob $(\mathrm{OR}=2.6,1.5-4.3$ and $\mathrm{OR}=3.5,2.4-5.1$, respectively), compared to children in the lowest quartile.

Physical activity variables (associated with ow/Ob at age 8) Children driven to school via motor vehicle had over 3 times the odds of ow/ob at age $5(\mathrm{OR}=3.4,2.1-5.0)$ and age $8(\mathrm{OR}=3.8,2.5-5.9)$. There was a negative association between ow/ob and the number of hours a child spent playing in the last week, at ages 5 and 8. However, the variable lost statistical significance after adjusting for sociodemographic factors. In lieu of a variable for the number of hours children spent watching television, the number of televisions in a household was used as a proxy. Children with 2 or more televisions in their homes at age 8 had nearly 5 times the odds of ow/ob $(\mathrm{OR}=4.9,1.4-17.4)$, compared to children with no television. 
Table 3 Parsimonious adjusted models (nutrition \& physical activity variables in multivariable analyses, adjusted for sociodemographic variables)

\begin{tabular}{|c|c|c|c|c|}
\hline & Variables & $\begin{array}{l}\text { Age } 1 \\
\text { OR }[95 \% \mathrm{Cl}]\end{array}$ & $\begin{array}{l}\text { Age } 5 \\
\text { OR }[95 \% \mathrm{Cl}]\end{array}$ & $\begin{array}{l}\text { Age } 8 \\
\text { OR }[95 \% \mathrm{Cl}]\end{array}$ \\
\hline \multirow[t]{27}{*}{ Nutrition Variables } & $\begin{array}{l}\text { length of breastfeeding } \\
\text { (ref is }<6 \text { months) }\end{array}$ & & & \\
\hline & $6-12$ months & $0.3[0.1-0.9]^{*}$ & & \\
\hline & $>12$ months & $0.4[0.2-0.9]^{* *}$ & & \\
\hline & $\begin{array}{l}\text { \# of times child ate/day } \\
\text { (ref is } 3 \text { times) }\end{array}$ & & & \\
\hline & $0-2$ times & & $0.6[0.3-1.1]$ & $1.9[0.2-18.8]$ \\
\hline & $4-5$ times & & $0.8[0.4-1.5]$ & $1.5[0.8-2.9]$ \\
\hline & $6+$ times & & $2.4[1.3-4.6]^{* * *}$ & $3.2[1.6-6.8]^{* * *}$ \\
\hline & $\begin{array}{l}\text { restaurant/food stalls } \\
\text { (ref is lowest quartile) }\end{array}$ & & & \\
\hline & 2nd quartile & & $1.2[0.6-2.5]$ & $1.4[0.8-2.4]$ \\
\hline & 3rd quartile & & $2.6[1.4-4.7]^{* * *}$ & $1.8[1.1-2.9]^{* *}$ \\
\hline & 4th quartile & & $4.6[2.6-8.2]^{* * *}$ & $2.6[1.5-4.3]^{* * *}$ \\
\hline & $\begin{array}{l}\text { powdered milk } \mathbf{k}^{\mathrm{b}, \mathrm{c}} \\
\text { (ref is lowest quartile) }\end{array}$ & & & \\
\hline & 2nd quartile & & $3.1[1.8-5.3]^{* * *}$ & \\
\hline & 3rd quartile & & $2.4[1.4-4.1]^{* * *}$ & \\
\hline & 4th quartile & & $2.8[1.6-4.6]^{* * *}$ & $1.8[1.1-3.0]^{*}$ \\
\hline & $\begin{array}{l}\text { milk/milk products } \\
\text { (ref is lowest quartile) }\end{array}$ & & & \\
\hline & 2nd quartile & & $1.4[0.8-2.6]$ & $0.9[0.5-1.5]$ \\
\hline & 3rd quartile & & $2.4[1.4-4.0]^{* * *}$ & $1.2[0.7-2.0]$ \\
\hline & 4th quartile & & $3.9[1.6-4.2]^{* * *}$ & $1.1[0.6-1.8]$ \\
\hline & $\begin{array}{l}\text { packaged sweets/ } \\
\text { snacks }^{\mathrm{b}} \\
\text { (ref is lowest quartile) }\end{array}$ & & & \\
\hline & 2nd quartile & & $1.4[0.9-2.3]$ & $2.1[1.4-3.2]^{* * *}$ \\
\hline & 3rd quartile & & $2.3[1.6-3.5]^{* * *}$ & $2.4[1.6-3.8]^{* * *}$ \\
\hline & 4th quartile & & $3.4[2.3-4.9]^{* * *}$ & $3.5[2.4-5.1]^{* * *}$ \\
\hline & $\begin{array}{l}\text { honey/sugar } \\
\text { (ref is lowest quartile) }\end{array}$ & & & \\
\hline & 2nd quartile & & $1.5[1.0-2.3]$ & $0.9[0.6-1.4]$ \\
\hline & 3rd quartile & & $2.0[1.3-3.2]^{* * *}$ & $1.0[0.5-2.0]$ \\
\hline & 4th quartile & & $2.7[1.8-4.1]^{* * *}$ & $1.5[0.9-5.1]$ \\
\hline \multirow[t]{10}{*}{$\begin{array}{l}\text { Physical Activity } \\
\text { Variables }\end{array}$} & $\begin{array}{l}\text { mode of transportation } \\
\text { (ref is walking) }\end{array}$ & & & \\
\hline & riding bike & & $1.3[0.8-2.1]$ & $1.6[0.9-2.7]$ \\
\hline & motorbike & & $3.4[2.1-5.0]^{* * *}$ & $3.8[2.5-5.9]^{* * *}$ \\
\hline & $\begin{array}{l}\text { hours child spent playing in last week } \\
\text { (ref is }<6 h)\end{array}$ & & & \\
\hline & $6-10 h$ & & $1.6[1.0-2.7]$ & $1.0[0.6-1.3]$ \\
\hline & 10h hours & & $1.2[0.7-2.1]$ & $0.6[0.5-1.1]$ \\
\hline & number of TVs owned in household & & & \\
\hline & (ref is 0$)$ & & & \\
\hline & $1 \mathrm{TV}$ & & $2.0[0.9-4.2]$ & $2.4[0.7-8.0]$ \\
\hline & $2+\mathrm{TV}$ & & $2.8[1.1-7.0]$ & $4.9[1.4-17.4]^{*}$ \\
\hline
\end{tabular}

aAll variables are adjusted for sex, site type, wealth index, and interaction term of wealth and site type

${ }^{b}$ The sample was divided into four equally sized groups or quartiles based on consumption within the last 2 weeks

'The sample for powdered milk at age 8 was divided into two equally sized groups above and below the median since it was not possible to divide it into quartiles

${ }^{*} p<0.05 ;{ }^{* *} p<0.01 ;{ }^{* * *} p<0.001$ 


\section{Multivariable models}

Table 4 shows the two models (as described in statistical analysis section above) used to control for multiple factors, in addition to sociodemographic variables, to identify contributions of each factor from our adjusted parsimonious model. Figure 3 summarizes the findings of the sociodemographic, nutrition, and physical activity variables associated with childhood obesity in this sample.

\section{Sociodemographic variables}

The only sociodemographic variable consistently associated with ow/ob across the two models was male sex-males had 2 to 3 times the odds of ow/ob compared to females. In model 2 , children whose mothers had high school or higher education had greater odds of ow/ob $(\mathrm{OR}=2.1,1.2-3.9)$.

\section{Nutrition variables}

In both models 1 and 2, children in the highest quartile for frequency of consumption of packaged sweets had higher odds of ow/ob in model $1(\mathrm{OR}=2.2,1.3-3.5)$ and model $2(\mathrm{OR}=1.9,1.1-3.3)$, compared to those in the lowest quartile.

\section{Physical activity variables}

Children driven to school via motor vehicle had higher odds of ow/ob in model $1(\mathrm{OR}=1.8,1.1-3.3)$ and model $2(\mathrm{OR}=3.5,1.8-6.7)$.

\section{Discussion}

In the longitudinal YLCS, following nearly 2000 children at 1,5 and 8 years of age from 2002 to 2009 , the prevalence of childhood ow/ob increased with age. The increase in obesity rate was steepest from age 1 to 5 (1.1

Table 4 Extended multivariable models of risk factors associated with child overweight/obesity at age 8

\begin{tabular}{|c|c|c|}
\hline Variables & $\begin{array}{l}\text { Model } 1 \text { (Age } 1 \& 5 \text { ) } \\
\text { Early factors } \\
\text { OR }[95 \% \text { Cl]; } n=726\end{array}$ & $\begin{array}{l}\text { Model } 2 \text { (Age } 1,5, \& 8) \\
\text { Combined Factors } \\
\text { OR }[95 \% \text { CI]; } n=1004\end{array}$ \\
\hline \multicolumn{3}{|l|}{ Social Demographics } \\
\hline wealth index & $1.1[1.0-1.2]$ & $1.0[0.9-1.1]$ \\
\hline sex (boy) & $3.2[1.9-5.3]^{* * *}$ & $2.4[1.4-4.3]^{* * *}$ \\
\hline site type (urban) & $1.4[0.2-9.9]$ & $0.2[0.0-3.1]$ \\
\hline $\begin{array}{l}\text { interaction term } \\
\text { (wealth index x site type) }\end{array}$ & $1.0[0.9-1.2]$ & $1.0[0.8-1.2]$ \\
\hline \multicolumn{3}{|l|}{ Round 3} \\
\hline number of TVs $(1+)^{\mathrm{a}}$ & & $2.6[0.8-2.3]$ \\
\hline transportation (motorbike) ${ }^{b}$ & & $3.5[1.8-6.7]^{* * *}$ \\
\hline times eaten $(6+\text { times })^{c}$ & & $1.8[0.9-3.5]$ \\
\hline packaged sweets $^{\mathrm{d}}$ & & $1.1[0.9-1.3]$ \\
\hline restaurant/stalls ${ }^{\mathrm{d}}$ & & $1.5[0.7-3.1]$ \\
\hline milk $^{d}$ & & $2.5[0.9-4.1]$ \\
\hline \multicolumn{3}{|l|}{ Round 2} \\
\hline transportation (motorbike) ${ }^{\mathrm{b}}$ & $1.8[1.1-3.3]^{*}$ & $1.4[0.6-3.1]$ \\
\hline times eaten $(6+\text { times })^{c}$ & $1.6[0.8-3.3]$ & $2.3[0.9-6]$ \\
\hline powdered milk ${ }^{d}$ & $1.5[0.8-2.7]$ & $1.4[0.7-2.8]$ \\
\hline packaged sweets $^{d}$ & $2.2[1.3-3.5]^{* *}$ & $1.9[1.1-3.3]^{*}$ \\
\hline sugar/honey ${ }^{d}$ & $1.2[0.6-2.0]$ & $1.3[0.8-2.4]$ \\
\hline \multicolumn{3}{|l|}{ Round 1} \\
\hline length of breastfeeding ${ }^{\mathrm{e}}$ & $0.5[0.1-2.2]$ & $0.4[0.1-1.5]$ \\
\hline mother's education $^{f}$ & $1.7[0.8-3.5]$ & $2.1[1.2-3.9]^{*}$ \\
\hline
\end{tabular}

${ }^{a}$ Number of TV household owned 1+ is compared to not owning any TV

${ }^{b}$ Mode of transportation via motorbike to school is compared to children who walk to school

'Number of times eaten (6+) is compared to baseline of eating 3 times a day

${ }^{d}$ Nutrition variables in these models are divided into two equally sized groups - above and below the median. The children who are above the median of

consumption are compared those below the median of consumption

eLength of breastfeeding is greater than 6 months compared to those who breastfed for 6 months or less

${ }^{f}$ Mother's education is comparing mothers with grade 10 or higher to those with less years of education

${ }^{*} p<0.05 ;{ }^{* *} p<0.01 ;{ }^{* * *} p<0.001$ 


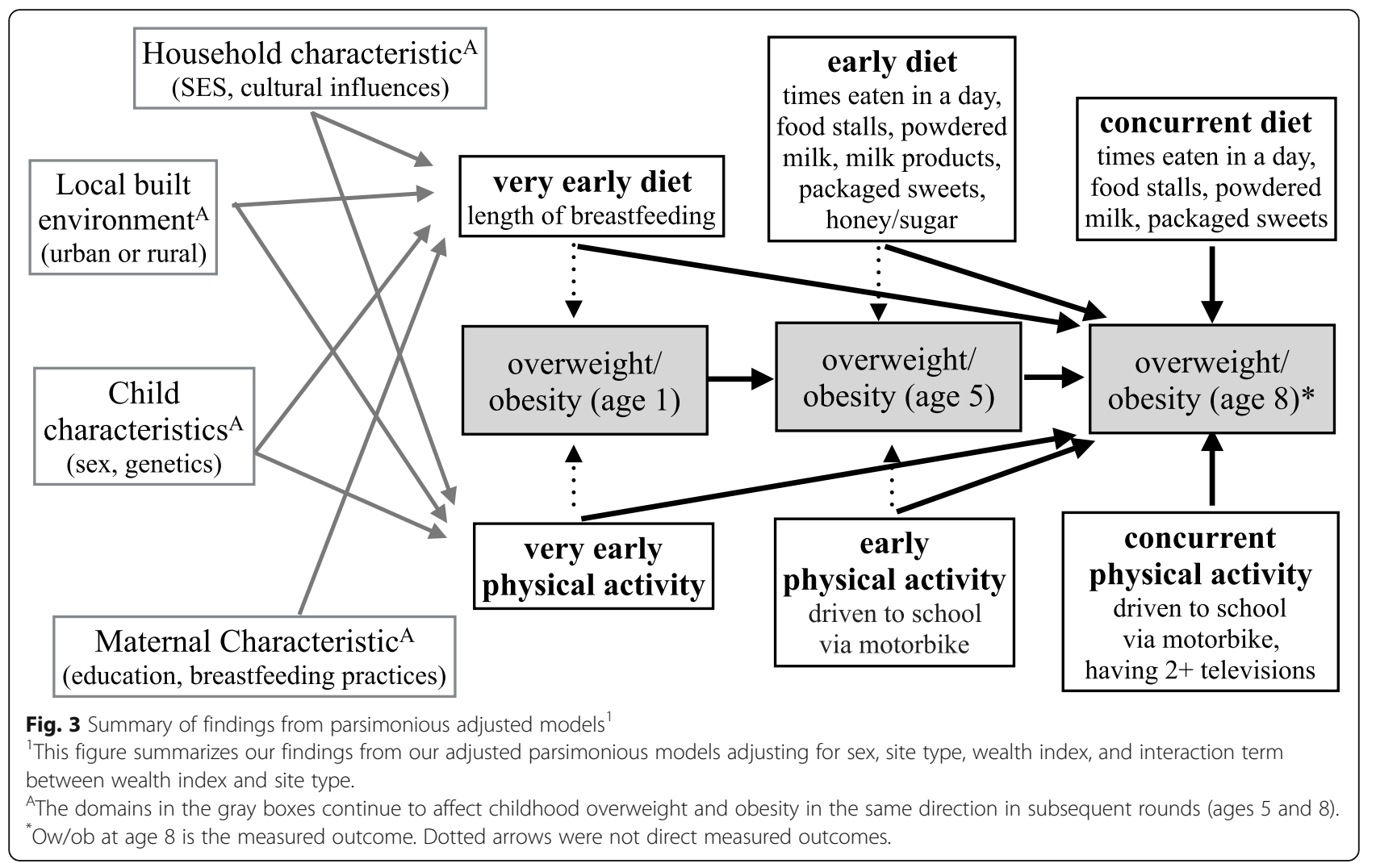

to $8.4 \%$ ), with a slower rate of increase from age 5 to 8 (8.4 to $10.3 \%)$. At age 1, the prevalence of ow/ob stratified by sex was not statistically significant, but by age 5 and 8 , rates were almost double for boys when compared to girls. Children in urban sites had 4 times the odds of being ow/ob, compared to rural sites. Furthermore, ow/ob was significantly associated with wealth index in both urban and rural sites, but the odds ratio was greater for urban sites than rural sites. Higher maternal education was also associated with greater odds for child ow/ob. We also found that half of the children with ow/ob at age 1 continued to be ow/ob at age 5 . And of the children with ow/ob at age 5, more than half continued to be ow/ob at age 8 .

The findings on prevalence of ow/ob at all ages in this sample from 2009 are lower when compared to the more recent cross-sectional studies of similar age groups in Vietnam. A 2016 survey of 2677 children age 3-6 years old in Hanoi shows the prevalence of ow/ob to be 16.7 and $4.5 \%$, respectively [27]. In the same year, a survey of children ages 7-9 years in Ho Chi Minh City using International Obesity Task Force cutoffs found the prevalence of overweight to be $30 \%$ and obesity to be $12.3 \%$ [18]. Ho Chi Minh City and Hanoi are both metropolitan areas, which may explain the higher rates of ow/ob in these studies. Meanwhile, the YLCS sampling methodology favored data from more rural communes. However, urban versus rural sampling may only partly explain this difference, as the more recent data may be consistent with the current trend of increasing rates of childhood ow/ob in Vietnam [28].

While other studies have identified numerous contributors to child obesity across community-, family- and child-level factors [29-31], we focused on child nutrition and physical activity factors that are potentially modifiable. In our bivariate and multivariable logistic regression models, the early childhood and concurrent nutritional risk factors associated with ow/ob at age 8 were frequent consumption of packaged sweets/snacks, powdered milk, milk/milk products, honey/sugar, restaurant/food stall food, and eating 6 or more times per day; while breastfeeding for more than 6 months was a protective nutrition factor. The key physical activity risk factors for ow/ob were motor vehicle transportation to school, and having two or more televisions in the home.

This study's findings of the prevalence of ow/ob, and the associated sociodemographic and behavioral factors, are consistent with findings of other cross-sectional studies in Vietnam [17, 18, 32, 33] and other LMICs [34-36]. In LMICs, higher rates of child ow/ob for families with greater wealth, particularly in urban areas, are likely attributable to globalization, economic growth and marketing-driven changes in child feeding practices (consumption of a greater quantity and frequency of 
calorie-dense food and beverages) [37, 38] and reduced physical activity (due to urban traffic with less opportunity to safely walk to school and play outdoors, and greater use of sedentary screen-based entertainment) $[29,39-41]$.

As LMICs' economic growth continues, the burden of ow/ob will likely shift from families in the higher economic strata to lower economic strata [42]. In a recently published paper, Templin et al. extrapolates from existing data to predict that the percent change in overweight prevalence among the relatively poor in Vietnam from 2016 to 2040 will be $80-100 \%$ [43]. This projection is alarming, as the Vietnamese government is still struggling to address stunting and wasting for children under 5 years of age from families of lower wealth [44].

Aside from wealth difference in association with ow/ ob at age 8, we also found sex difference, in which more boys were ow/ob at age 5 and age 8 . In Vietnam, boys may have higher ow/ob odds due to historical and cultural male-gender preferences [45], possibly leading families to devote more resources to boys in regards to feeding practices. Furthermore, this difference may be a consequence of culturally embedded preferences for "thinner" girls and "bigger" boys [46].

Longer breastfeeding was found to be a protective nutrition factor, consistent with previous literature from many other countries [47-49], possibly since longer breastfeeding may preclude excessive bottle-feeding and inappropriate complementary feeding practices that predispose the child to obesity in early childhood [50]. Although high rates of breastfeeding are reported in this study, bottlefeeding and supplemental feeding practices are not recorded. Other studies show high rates of mixed feeding [51] and bottle-feeding [52] in Vietnam - especially supplemental feeding with sweetened liquids and foods [53] that is associated with increased risk of child obesity [54]. Children of mothers with higher education may have greater risk of ow/ob because educated mothers may be working outside the home, curtailing the duration of breastfeeding, and leaving the child's caregiver with money to buy "treats" such as snacks or sugary drinks $[55,56]$. Furthermore, the common practice of giving children sweets as a reward leads children to associate sugary foods and beverages with positive emotions, and reduces preference for non-sugary options such as vegetables, unsweetened milk, and water [57-59].

In Vietnam, economic growth is a major driver of increased availability of ultra-processed snack foods, fast foods, and sugar-sweetened milk. The 2016 USDA Foreign Agriculture Service Report reported that Vietnam is the 13th largest export market for food and beverages from the United States, and that Vietnam's sizable young population, rising middleclass incomes, and female labor force participation may be driving consumerism and preferences for processed, packaged products and fast food chains [60]. With the increase in accessibility of Westernstyle fast food [61] and dietary pattern changes due to increased consumption of processed foods [62], Vietnamese children now have access to more processed snacks and fast foods. This may explain our findings that children who eat snacks, eat more frequently, and eat out in food stalls/restaurants have higher odds of being ow/ob. Aside from snacking, eating more frequently is dependent on caretakers' feeding practices. In a cross-sectional study on parents' feeding practices and their association to childhood obesity, Do et al. found children of mothers in rural area of Hanoi were more likely to eat larger amounts of food, with high intake of fatty foods and protein, when compared to children of mothers in the urban environment of Hanoi [63]. The paper hypothesized that this may be a result of "pressure to eat" feeding practices of mothers in rural area stemming from fear of malnutrition, and consequently leading to both increased amounts of food and higher intake of fatty foods [63].

In this study, we also found that children who drink powdered milk and milk products have higher odds of being ow/ob at age 8 . In a recent qualitative study by Do et al., mothers acknowledged that one way to improve children's diets is to switch from milk with sugar to milk without sugar [55]. While milk and powdered milk have some nutritional benefits, the sugar and other additives may be a significant contributor to excess weight gain. There is substantial evidence that consumption of sugarsweetened beverages, including sugary milk, contributes to the epidemic of child ow/ob [64, 65]. However, sugary milk consumption has been understudied, and unfortunately the YLCS did not specify in the questionnaire if milk contained sugar or not.

Aside from nutrition, physical inactivity and sedentary behaviors have been identified as major risk factors contributing to increase in ow/ob in LMICs [41]. Since the dataset did not include direct measures of daily physical activity, children who were being driven to school via motorbike was used as a proxy for decreased physical activity, with findings suggesting that children who were driven to school have higher odds of being ow/ob in YLCS. From interviews with parents, Trang et al. found that lack of pathways and dangerous traffic were among the reasons many parents did not let their children walk or cycle to school in Ho Chi Minh City [17]. Decreases in walkability of cities in Vietnam [66], in combination with increases in screen time [67], are leading to an increase in sedentary behaviors amongst children in Vietnam, which subsequently contribute to the rising trend of ow/ob. 
Overall, this study supports and adds to previous findings that early childhood parenting practices around child nutrition and physical activity-and the environmental and cultural context-play a crucial role in contributing to child ow/ob, and may be important targets for interventions to prevent child ow/ob. Additionally, these interventions should aim to reach groups that are at greatest risk of developing child ow/ob, specifically children who are boys, from families of higher economic strata, and living in urban settings.

\section{Study strengths and limitations}

The strengths of this study include utilizing the YLCS, a large geographically-representative 8-year longitudinal cohort dataset, with very low attrition (1.5\%), enabling investigation of a wide variety of sociodemographic and behavioral risk factors for child overweight/obesity at ages 1, 5, and 8 - which, before this study, had not been done. Our study focused on potentially-modifiable nutrition variables-identified as very early factors (age 1), early factors (age 5) and concurrent factors (age 8)-associated with child ow/ob at age 8 . We utilized parsimonious models adjusting for sociodemographic factors and extended models adjusting for very early life, early and concurrent sociodemographic and behavioral factors.

The limitations of this study include the secondary analysis of an existing dataset that is over 10 years old and not specifically designed to include all variables relevant to child obesity, especially daily physical activity. Furthermore, the dataset does not include structural variables such as food supply and access, which is a function of structural constraints in childhood obesity [68]. BMI-forage is a simple and useful, but imperfect, proxy for identifying child adiposity and related health risks [69]. The main limitation of the extended models is that multicollinearity may have reduced the statistical significance for significant variables in the prior adjusted models. The significant associations identified in this study do not prove causation of the outcomes, although the temporality of pre-existing factors before the outcomes in this longitudinal study adds further support for the hypothesis, beyond the findings of cross-sectional studies. In regards to physical activity variables assessed in our analyses, these were not direct measurements of physical activity, but were instead proxy variables used in substitution as YLCS's surveys did not address children's physical activity levels. Finally, while the pro-rural sampling in the YLCS facilitated urban vs. rural analysis, weights were not provided to correct for this; therefore, it is not possible to accurately generalize our findings to the population nationwide in Vietnam. In comparison to Vietnam's 2002 Demographic and Health Survey and 2002 Vietnam
Housing Living Standard Survey, households in YLCS on average were slightly poorer and owned fewer assets [19].

\section{Conclusions}

This longitudinal, geographically-representative study in Vietnam found a high prevalence of early childhood ow/ob, increasing dramatically between 1 and 8 years of age. Sociodemographic risk factors included male sex, higher family wealth, higher maternal education, and urban location. Nutritional risk factors included frequent meals and frequent consumption of milk/milk products, sweets, packaged snacks, and food from restaurants/food stalls, while longer duration of breastfeeding was protective. Physical activity risk factors included being driven to school and having multiple televisions in the home.

There is an urgent need for policies and interventions to prevent child obesity in Vietnam-particularly focused on early childhood from age 1-5 years-with support for healthy parenting practices regarding nutrition and physical activity. These include limiting the marketing of unhealthy products (including sugar-sweetened milk) to children and parents, prohibiting the sale of unhealthy foods and beverages in and around schools and health facilities, increasing public media and education of parents in maternal-child health programs and preschools regarding longer breastfeeding, limiting obesogenic foods/drinks and screen time, and increasing physical activity.

\section{Supplementary Information}

The online version contains supplementary material available at https://doi. org/10.1186/s12889-021-10292-z.

Additional file 1 Table S2.1. Bivariate associations with overweight and obesity at Round 3 (age 8). Table S3.1: Frequencies of Nutrition \&

Physical Activity Variables.

\begin{abstract}
Abbreviations
Ow/ob: Overweight and obese; LMIC: Low- and middle-income countries; BMI: Body mass index; WHO: World Health Organization; YLCS: Young Lives Cohort Study
\end{abstract}

\section{Acknowledgements}

Thank you to all the mothers and children who participated in the Young Lives Cohort Study.

\section{Authors' contributions}

TN completed literature review, analyzed and interpreted the data, and drafted manuscript. KS, ML, SI, LF supported TN in refining the research question and interpreting findings. LF obtained the data. KS and SI supported TN with literature review. ML analyzed and interpreted dataset using STATA 15 with TN. TN drafted the manuscript and all co-authors substantively revised it. All authors read and approved the final manuscript.

\section{Funding}

Funding was provided by the UC Berkeley-UCSF Joint Medical Program thesis grant and the Schoenemann grant for purchase of hardware (computer) and software (STATA15 program) used for this study. The UC Berkeley-UCSF Joint Medical Program and Schoenemann Foundation did not have any role 
in the design of the study, data collection, analysis, interpretation of data, or in writing the manuscript.

\section{Availability of data and materials}

The datasets generated and/or analyzed in the current study are available in the Young Lives Cohort Study repository through UK Data Service, https:// www.younglives.org.uk. Datasets from UK Data Service are open to public access through three tiers of access: tier 1 - open (de-identified data with low risk of disclosure), tier 2 - safeguarded (de-identified data but at risk of disclosure due to linkage to other data), and tier 3 - controlled (data that may be identifiable and are at high risk of disclosure). For this study, we registered and were approved by UK Data Service for tier 1 access, which is open to the general public.

\section{Ethics approval and consent to participate}

The Oxford University and Hanoi School of Public Health ethics committees reviewed and approved the YLCS. Parents gave written consent in round 1 and subsequent verbal consent in later rounds. The UC Berkeley's Committee for the Protection of Human Subjects reviewed and deemed that our study did not meet the threshold definition of "human subjects" according to Federal Regulations at 45 CFR 46.102(f); therefore, we did not need to obtain institution review board's approval for this study.

\section{Consent for publication}

Not Applicable.

\section{Competing interests}

The authors declare that they have no competing interests.

\section{Author details}

${ }^{1}$ School of Public Health and School of Medicine, UC Berkeley-UCSF Joint Medical Program, University of California, 2121 Berkeley Way, Room 5302, Berkeley, CA, USA. ${ }^{2}$ School of Public Health, UC Berkeley-UCSF Joint Medical Program, University of California, 570 University Hall, MC 1190, Berkeley, CA, USA. ${ }^{3}$ Division of Epidemiology and Biostatistics, School of Public Health, University of California, 6132 Berkeley Way West, Berkeley, CA, USA. ${ }^{4}$ School of Public Health, University of California, 2121 Berkeley Way, Room 5302, Berkeley, CA, USA. ${ }^{5}$ School of Public Health, UC Berkeley-UCSF Joint Medical Program, University of California, 2199 Addison St, 4th floor, Berkeley, CA, USA.

Received: 29 May 2020 Accepted: 20 January 2021 Published online: 05 February 2021

\section{References}

1. Fan P, Ouyang Z, Dinh Duong N, Nguyen H, Park H, Chen J. Urbanization, economic development, environmental and social changes in transitional economies: Vietnam after Doimoi. Landsc Urban Plan. 2018. https://doi.org/ 10.1016/j.landurbplan.2018.10.014

2. Popkin BM, Corvalan C, Grummer-Strawn LM. Dynamics of the double burden of malnutrition and the changing nutrition reality. Lancet. 2020; 395(10217):65-74. https://doi.org/10.1016/S0140-6736(19)32497-3.

3. WHO. Viet Nam Nutrition Profile - Global Nutrition Report. 2018. https:// globalnutritionreport.org/resources/nutrition-profiles/asia/south-eastern-asia/ viet-nam/.

4. Raghuveer G. Lifetime cardiovascular risk of childhood obesity. Am J Clin Nutr. 2010;91(5):1514-9. https://doi.org/10.3945/ajcn.2010.28701D.

5. Sahoo K, Sahoo B, Choudhury AK, Sofi NY, Kumar R, Bhadoria AS. Childhood obesity: causes and consequences. J Fam Med Prim care. 2015;4(2):187-92. https://doi.org/10.4103/2249-4863.154628.

6. Berenson GS. Health consequences of obesity. Pediatr Blood Cancer. 2012; 58(1):117-21. https://doi.org/10.1002/pbc.23373.

7. Freedman DS, Khan LK, Dietz WH, Srinivasan SR, Berenson GS. Relationship of childhood obesity to coronary heart disease risk factors in adulthood: the Bogalusa heart study. Pediatrics. 2001;108(3):712-8. https://doi.org/10.1542/ peds.108.3.712.

8. Dabelea D, Mayer-Davis EJ, Saydah S, et al. Prevalence of type 1 and type 2 diabetes among children and adolescents from 2001 to 2009. Jama. 2014; 311(17):1778. https://doi.org/10.1001/jama.2014.3201.

9. Reilly JJ, Kelly J. Long-term impact of overweight and obesity in childhood and adolescence on morbidity and premature mortality in adulthood: systematic review. Int J Obes. 2011;35(7):891-8. https://doi.org/10.1038/ijo. 2010.222.

10. Hanh NTH, Tuyet LT, Dao DTA, Tao Y, Chu D-T. Childhood Obesity Is a High-risk Factor for Hypertriglyceridemia: A Case-control Study in Vietnam. Osong Public Heal Res Perspect. 2017;8(2):138-46. https://doi.org/10.24171/j.phrp.2017.8.2.06.

11. Sievert $K$, Lawrence $M$, Naika A, Baker P. Processed foods and nutrition transition in the pacific: Regional trends, patterns and food system drivers. Nutrients. 2019;11(6). https://doi.org/10.3390/nu11061328.

12. Gouel C, Guimbard H. Nutrition transition and the structure of global food demand. Am J Agric Econ. 2019;101(2):383-403. https://doi.org/10.1093/ ajae/aay030.

13. Aurino E, Fernandes M, Penny ME. The nutrition transition and adolescents' diets in low- and middle-income countries: a cross-cohort comparison. Public Health Nutr. 2017;20(1):72-81. https://doi.org/10.1017/S1368980016001865.

14. Janssen I, Katzmarzyk PT, Boyce WF, et al. Comparison of overweight and obesity prevalence in school-aged youth from 34 countries and their relationships with physical activity and dietary patterns. Obes Rev. 2005;6(2): 123-32. https://doi.org/10.1111/j.1467-789X.2005.00176.x.

15. Devís-Devís J, Lizandra J, Valencia-Peris A, Pérez-Gimeno E, García-Massò X, PeiróVelert C. Longitudinal changes in physical activity, sedentary behavior and body mass index in adolescence: migrations towards different weight cluster. PLoS One 2017;12(6):1-15. https:/doi.org/10.1371/journal.pone.0179502.

16. Le Nguyen BK, Le Thi H, Nguyen Do VA, et al. Double burden of undernutrition and overnutrition in Vietnam in 2011: results of the SEANUTS study in 0.5-11-year-old children. Br J Nutr. 2013;110(S3):S45-56. https://doi. org/10.1017/S0007114513002080.

17. Trang NHHD, Hong TK, Dibley MJ. Cohort profile: Ho Chi Minh City youth cohort-changes in diet, physical activity, sedentary behaviour and relationship with overweight/obesity in adolescents. BMJ Open. 2012;2(1):18. https://doi.org/10.1136/bmjopen-2011-000362.

18. Pham NK, Sepehri A, Le TM, Tran VT. Correlates of body mass index among primary school children in Ho Chi Minh City, Vietnam. Public Health. 2020; 181:65-72. https://doi.org/10.1016/j.puhe.2019.12.007.

19. Nguyen NP. An assessment of the young lives sampling approach in Vietnam. Young Lives Tech Note. 2008;1(March):1-37.

20. WHO. AnthroPlus for Personal Computers. Manual: Software for assessing growth of the world's children and adolescents, vol. 2009. Geneva; 2009. p. 1-45. http://www.who.int/growthref/tools/en/

21. Organization WH. WHO Child Growth Standards. Vol 51; 2014. https://doi. org/10.1111/j.1469-8749.2009.03503.x.

22. World Health Organization \& UNICEF. Recommendations for Data Collection, Analysis and Reporting on Anthropometric Indicators in Children under 5 Years Old.; 2019.

23. de Onis M. Development of a WHO growth reference for school-aged children and adolescents (5-19 years of age). Bull World Health Organ. 2007; 85:660-7. https://doi.org/10.2471/BLT.

24. Boyden J. Young Lives: an International Study of Childhood Poverty: Rounds 1-5 Constructed File, 2002-2016. data Collect. 2018;(September):32.

25. Briones K. 'How Many Rooms Are There in Your House ?' Constructing the Young Lives Wealth Index. Young Lives Tech Note. 2017;(November). https://assets. publishing.service.gov.uk/media/5acb49bce5274a7f20e712c1/YL-TN43_0.pdf.

26. Martel P. Review of options for reporting water, Sanitation and Hygiene Coverage By Wealth Quintile.; 2016. http://mics.unicef.org/files?job=W1 siZilsljlwMTcvMDYvMTUvMTYvMzMvMzAvMzE2L01JQ1NfTWVOaG9kb2xvZ2 ljYWxfUGFwZXJfNC5wZGYiXV0\&sha=adfd855d58aa27ea.

27. Do LM, Tran TK, Eriksson B, Petzold M, Ascher H. Prevalence and incidence of overweight and obesity among Vietnamese preschool children: a longitudinal cohort study. BMC Pediatr. 2017;17(1):1-10. https://doi.org/10. 1186/s12887-017-0904-y.

28. Schott W, Aurino E, Penny ME, Behrman JR. The double burden of malnutrition among youth: trajectories and inequalities in four emerging economies. Econ Hum Biol. 2019;34:80-91. https://doi.org/10.1016/j.ehb.2019.05.009.

29. Galvez MP, Pearl M, Yen $1 \mathrm{H}$. Childhood obesity and the built environment: a review of the literature from 2008-2009. Curr Opin Pediatr. 2010;22(2):202-7. https://doi.org/10.1097/MOP.0b013e328336eb6f.Childhood.

30. Boonpleng W, Park CG, Gallo AM, Corte C, McCreary L, Bergren MD. Ecological influences of early childhood obesity: a multilevel analysis. West J Nurs Res. 2013;35(6):742-59. https://doi.org/10.1177/0193945913480275.

31. McBride B, Fiese B, Dev DA, et al. Risk factors for overweight/obesity in preschool children: An ecological approach. Child Obes. 2013;9(5):399-408. https://doi.org/10.1089/chi.2012.0150. 
32. Mai TMT, Pham NO, Tran TMH, et al. The double burden of malnutrition in Vietnamese school-aged children and adolescents: a rapid shift over a decade in $\mathrm{Ho}$ Chi Minh City. Eur J Clin Nutr. 2020. https://doi.org/10.1038/s41430-020-0587-6.

33. Ngan HTD, Tuyen LD, Van Phu P, Nambiar S. Childhood overweight and obesity amongst primary school children in Hai Phong City, Vietnam. Asia Pac J Clin Nutr. 2018;27(2):399-405. https://doi.org/10.6133/apjen.062017.08.

34. Dinsa GD, Goryakin Y, Fumagalli E, Suhrcke M. Obesity and socioeconomic status in developing countries: a systematic review. Obes Rev. 2012;13(11): 1067-79. https://doi.org/10.1111/j.1467-789X.2012.01017.x

35. Uusitalo U, Sobal J, Moothoosamy L, et al. Dietary westernisation: conceptualisation and measurement in Mauritius. Public Health Nutr. 2005; 8(06):608-19. https://doi.org/10.1079/PHN2004716.

36. Poskitt EME. Countries in transition: underweight to obesity non-stop? Ann Trop Paediatr. 2009;29(1):1-11. https://doi.org/10.1179/146532809X401971.

37. An R, Shen J, Bullard T, Han Y, Qiu D, Wang S. A scoping review on economic globalization in relation to the obesity epidemic. Obes Rev. 2020; 21(3):1-11. https://doi.org/10.1111/obr.12969.

38. Gayathri R, Ruchi V, Mohan V. Impact of Nutrition Transition and Resulting Morbidities on Economic and Human Development. Curr Diabetes Rev. 2016;13(5). https://doi.org/10.2174/1573399812666160901095534.

39. Spence JC, Cutumisu N, Edwards J, Evans J. Influence of neighbourhood design and access to facilities on overweight among preschool children. Int J Pediatr Obes. 2008;3(2):109-16. https://doi.org/10.1080/ 17477160701875007 .

40. Prentice-dunn H, Prentice-dunn S. Physical activity, sedentary behavior, and childhood obesity : A review of cross-sectional studies. Psychol Health Med. 2012;17(3):255-73. https://doi.org/10.1080/13548506.2011.608806

41. Gupta N, Goel K, Shah P, Misra A. Childhood obesity in developing countries: epidemiology, determinants, and prevention. Endocr Rev. 2012; 33(1):48-70. https://doi.org/10.1210/er.2010-0028.

42. Goryakin Y, Lobstein T, James WPT, Suhrcke M. The impact of economic, political and social globalization on overweight and obesity in the 56 low and middle income countries. Soc Sci Med. 2015;133:67-76. https://doi.org/ 10.1016/j.socscimed.2015.03.030.

43. Templin T, Hashiguchi TCO, Thomson B, Dieleman J, Bendavid E. The overweight and obesity transition from the wealthy to the poor in low- and middleincome countries: a survey of household data from 103 countries. PLoS Med. 2019;16(11):1-15. https://doi.org/10.1371/journal.pmed.1002968.

44. WHO. Global Nutrition Report; 2018 - Executive Summary. 2018:12. https:// doi.org/10.2499/9780896295643.

45. Nanda P, Gautam MA, Verma R, Hong KT, Linh MTG, Puri M, et al. Study on Gender, Masculinity and Son Preference in Nepal and Vietnam. Int Cent Res Women New Delhi India. 2012; Available from: https://www.researchgate. net/publication/272356023_Study_on_Gender_Masculinity_and_Son_ Preference_in_Nepal_and_Vietnam.

46. Sano A, Le DSNT, Tran MHT, et al. Study on factors of body image in Japanese and Vietnamese adolescents. J Nutr Sci Vitaminol (Tokyo). 2008; 54(2):169-75. https://doi.org/10.3177/jnsv.54.169.

47. Eriksen KG, Lind MV, Larnkjær A, Mølgaard C, Michaelsen KF. Early Nutrition and Its Effect on Growth, Body Composition and Later Obesity. World Rev Nutr Diet. 2018;117(iii):111-28. https://doi.org/10.1159/000484502.

48. Zheng M, Cameron AJ, Birken CS, et al. Early infant feeding and BMl trajectories in the first 5 years of life. Obesity. 2020;28(2):339-46. https://doi. org/10.1002/oby.22688.

49. Rito Al, Buoncristiano M, Spinelli A, et al. Association between characteristics at birth, breastfeeding and obesity in 22 countries: the WHO European childhood obesity surveillance initiative - COSI 2015/2017. Obes Facts. 2019; 12(2):226-43. https://doi.org/10.1159/000500425.

50. Gibbs BG, Forste R. Socioeconomic status, infant feeding practices and early childhood obesity. Pediatr Obes. 2014;9(2):135-46. https://doi.org/10.1111/j. 2047-6310.2013.00155.x.

51. Leow TYQ, Ung A, Qian S, et al. Exploring infant feeding practices: crosssectional surveys of South Western Sydney, Singapore, and Ho Chi Minh City. BMC Pediatr. 2017;17(1):1-13. https://doi.org/10.1186/s12887-017-0902-0.

52. Huang D, Sokal-Gutierrez K, Chung K, et al. Maternal and child nutrition and oral health in urban Vietnam. Int J Environ Res Public Health. 2019;16(14):58. https://doi.org/10.3390/ijerph16142579.

53. Lundberg PC, Ngoc Thu TT. Breast-feeding attitudes and practices among Vietnamese mothers in Ho Chi Minh City. Midwifery. 2012;28(2):252-7. https://doi.org/10.1016/j.midw.2011.02.012
54. Pan L, Li R, Park S, Galuska DA, Sherry B, Freedman DS. A longitudinal analysis of sugar-sweetened beverage intake in infancy and obesity at 6 years. Pediatrics. 2014; 134(September):S29-35. https://doi.org/10.1542/peds.2014-0646F.

55. Do LM, Larsson V, Tran TK, Nguyen HT, Eriksson B, Ascher H. Vietnamese mother's conceptions of childhood overweight: Findings from a qualitative study. Glob Health Action. 2016;9(1). https://doi.org/10.3402/gha.v9.30215.

56. Babington L, Patel B. Understanding child feeding practices of Vietnamese mothers. MCN Am J Matern Child Nurs. 2008;33(6):376-81. https://doi.org/ 10.1097/01.NMC.0000341259.03298.26.

57. Benton D. Role of parents in the determination of the food preferences of children and the development of obesity. Int J Obes. 2004;28:858-69. https://doi.org/10.1038/sj.ijo.0802532.

58. Zadka K, Pałkowska-Goździk E, Rosołowska-Huszcz D. Family factors associated with selected childhood nutrition aspects in central Poland. Int J Environ Res Public Health. 2019;16(4). https://doi.org/10.3390/ ijerph16040541.

59. Woo T, Lee $\mathrm{KH}$. Exploring parenting variables associated with sweetness preferences and sweets intake of children. Nutr Res Pract. 2019;13(2):169-77. https://doi.org/10.4162/nrp.2019.13.2.169.

60. Vo K, Francic M. Vietnam Retail Foods - Sector Report 2016. Ha Noi; 2017. https://apps.fas.usda.gov/newgainapi/api/report/ downloadreportbyfilename?filename=Retail Foods_Hanoi_Vietnam_11-132018.pdf.

61. Asia Plus Inc. Q \& Me Vietnam Market Research, (2016). [online] Available at: https://qandme.net/en/report/Fast-food-eating-behavior-and-popularchains. html [Accessed 03 March, 2019].

62. Vietnam Ministry of Health. Summary Report - General Nutrition Survey 2009-2010; 2012. p. 1-30.

63. Do LM, Eriksson B, Tran TK, Petzold M, Ascher H. Feeding of preschool children in Vietnam: a study of parents' practices and associated factors. BMC Nutr. 2015;1(1):1-10. https://doi.org/10.1186/s40795-015-0011-0.

64. Malik VS, Schulze MB, Hu FB. Review Article Intake of sugar-sweetened beverages and weight gain. Am J Clin Nutr. 2006:84:274-88.

65. Pereira M. The possible role of sugar-sweetened beverages in obesity etiology : a review of the evidence. Int J Obes. 2006:28-36. https://doi.org/ 10.1038/sj.ijo.0803489.

66. Leather J, Fabian H, Gota S, Mejia A. Walkability and pedestrian facilities in Asian cities state and issues. Asian Dev Bank Sustain Dev Work Pap Ser. 2011;17:69.

67. Nguyen PVN, Hong TK, Nguyen DT, Robert AR. Excessive screen viewing time by adolescents and body fatness in a developing country: Vietnam. Asia Pac J Clin Nutr. 2016;25(1):174-83. https://doi.org/10.6133/apjcn.2016.25.1.21.

68. Huang H, Wan Mohamed Radzi CWJ bt, Jenatabadi HS. Family environment and childhood obesity: A new framework with structural equation modeling. Int J Environ Res Public Health. 2017:14(2). https:/doi.org/10.3390/ijerph14020181.

69. Hall DMB CT. What use is BMI? Arch Dis Child. 2006;91:283-6.

\section{Publisher's Note}

Springer Nature remains neutral with regard to jurisdictional claims in published maps and institutional affiliations.
Ready to submit your research? Choose BMC and benefit from:

- fast, convenient online submission

- thorough peer review by experienced researchers in your field

- rapid publication on acceptance

- support for research data, including large and complex data types

- gold Open Access which fosters wider collaboration and increased citations

- maximum visibility for your research: over $100 \mathrm{M}$ website views per year

At $\mathrm{BMC}$, research is always in progress.

Learn more biomedcentral.com/submission 